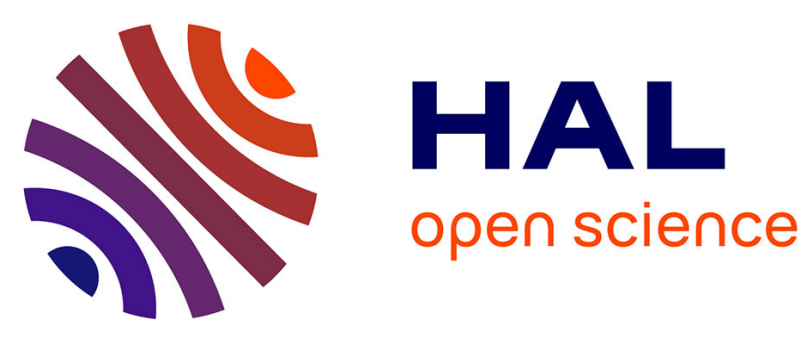

\title{
Molecular characterisation of birch bark tar by headspace solid-phase microextraction gas chromatography-mass spectrometry: A new way for identifying archaeological glues
}

\author{
M. Regert, V. Alexandre, Nicolas Thomas, A. Lattuati-Derieux
}

\section{To cite this version:}

M. Regert, V. Alexandre, Nicolas Thomas, A. Lattuati-Derieux. Molecular characterisation of birch bark tar by headspace solid-phase microextraction gas chromatography-mass spectrometry: A new way for identifying archaeological glues. Journal of Chromatography A, 2006, 1101 (1-2), pp.245-253. 10.1016/j.chroma.2005.09.070 . hal-01766864

\section{HAL Id: hal-01766864 https://hal-inrap.archives-ouvertes.fr/hal-01766864}

Submitted on 23 Apr 2018

HAL is a multi-disciplinary open access archive for the deposit and dissemination of scientific research documents, whether they are published or not. The documents may come from teaching and research institutions in France or abroad, or from public or private research centers.
L'archive ouverte pluridisciplinaire HAL, est destinée au dépôt et à la diffusion de documents scientifiques de niveau recherche, publiés ou non, émanant des établissements d'enseignement et de recherche français ou étrangers, des laboratoires publics ou privés. 


\title{
Molecular characterisation of birch bark tar by headspace solid-phase microextraction gas chromatography-mass spectrometry: A new way for identifying archaeological glues
}

\author{
M. Regert ${ }^{\mathrm{a}, *}$, V. Alexandre ${ }^{\mathrm{a}, \mathrm{b}}, \mathrm{N}$. Thomas ${ }^{\mathrm{c}}$, A. Lattuati-Derieux ${ }^{\mathrm{b}}$ \\ ${ }^{a}$ UMR 171 CNRS and GdR 2114 ChimArt, Centre de Recherche et de Restauration des Musées de France (C2RMF), \\ Palais du Louvre, Porte des Lions, 14 Quai François Mitterrand, F-75001 Paris, France \\ ${ }^{\mathrm{b}}$ FRE 2743 CNRS and GdR 2114 ChimArt, Centre de Recherches sur la Conservation des Documents Graphiques, \\ 36 Rue Geoffroy Saint-Hilaire, F-75005 Paris, France \\ c Institut National de Recherches Archéologiques Préventives, Université Paris I Panthéon-Sorbonne, Équipe d'Histoire des Techniques, \\ UMR 8589 CNRS, LAMOP and GdR 2114 ChimArt, Paris, France
}

Received 13 July 2005; received in revised form 31 August 2005; accepted 26 September 2005

Available online 19 October 2005

\begin{abstract}
To develop an analytical methodology, as non-destructive as possible, suitable for the identification of natural substances from archaeological origin, we studied the potentiality of solid-phase microextraction (SPME) for analysing birch bark tar, an adhesive commonly used during ancient times. First of all, birch bark tars were produced by a controlled heating of birch bark. The two kinds of samples obtained using different processes of fabrication, one at liquid state, the second one at solid state, were then analysed by headspace HS-SPME-GC-MS. Different conditions of sample treatment were tested (two different fibre coatings, various times and temperatures of extraction) in order to suggest optimal conditions for the analysis of birch bark tar. Both samples were shown to be rich in volatile organic components. Two main groups of constituents, namely phenolic compounds issued from lignin or tannin known to be present in bark and sesquiterpenoid hydrocarbons, secondary metabolites largely distributed in the plant kingdom, were detected for the first time in birch bark tar. HS-SPME-GC-MS appears thus to be a very efficient method for investigating the volatiles emitted by plant tars and could be further used for the study of birch bark tar samples issued from archaeological context.
\end{abstract}

(C) 2005 Elsevier B.V. All rights reserved.

Keywords: HS-SPME GC-MS; Birch bark tar; Phenols; Sesquiterpenes

\section{Introduction}

Birch bark tar is a sticky material that has been used for long time since prehistoric times [1-12]. This substance is manufactured by a controlled heating of white birch bark which allows to obtain an adhesive used for hafting lithic tools on wooden shaft or for repairing and decorating ceramic vessels. At archaeological sites, glue residues look like brown or black amorphous materials adhering to various lithic and bone tools or to ceramic vessels. First attempts to identify such materials were achieved during the 60 s by infrared spectroscopy $[13,14]$. With

\footnotetext{
* Corresponding author. Tel.: +331402068 57; fax: +33147033246.

E-mail address: martine.regert@ culture.fr (M. Regert).
}

the extension of the fields of application of gas chromatographic procedures during the $80 \mathrm{~s}$, birch bark tar was then identified after solvent extraction and derivatisation by GC and GC-MS, owing to a series of characteristic triterpenoid markers with a lupane skeleton $[6,9,10,12,15]$. At the same time, several processes of birch bark tar production were tested $[6,16]$. During such experiments, it was noticed that the tar obtained emitted a strong and aromatic smell that could be useful for characterising birch bark tar using volatile organic compounds (VOCs).

Over the past decade, the development by Pawliszyn and co-workers of a new sample treatment, rapid, solventless and non-destructive, namely solid-phase microextraction (SPME), has allowed the trapping of volatile organic compounds on a fibre coating followed by their identification by GC or GC-MS analysis [17]. SPME has then been rapidly applied to a wide range 
of matrices and analytes, samples and individual compounds for characterising materials as various as food commodities and beverage [18-21], pollutants [22], drugs [23], pharmaceuticals [24] or natural substances [25,26]. Very recently, a few studies have also been developed in the field of cultural heritage for identifying archaeological resins [27] or for studying the volatile components emitted by pulp-paper from an old book [28].

Because birch bark tar is a very odoriferous substance that was widely used during the past in a large range of activities, it appears that detecting and identifying the volatile organic components emitted by this material is of great interest for the characterisation of this substance in archaeological context, since it minimises the pretreatment step. SPME procedure indeed allows to trap the volatile components on a fibre coating and to analyse them after a thermal desorption in the injector chamber of the gas chromatograph. This method is thus a fast screening and sensitive analysis which does not alter the initial sample that can be used thereafter for complementary investigations.

The objective of this study was to assess the nature of the VOCs emitted by birch bark tar and to examine the feasibility of using headspace SPME-GC-MS for identifying this material. With this aim, we produced liquid birch bark tar using methods known to have been used during the past. Another substance, a solid birch bark tar synthetised a few years ago in the laboratory, was also investigated in this study. These samples were analysed by HS-SPME-GC-MS after optimising the extraction conditions.

\section{Experimental}

SPME-GC-MS analyses were performed on contemporary birch bark tars produced in various conditions (see sample description in Section 2.1). To compare the materials obtained with archaeological birch bark tar, we first analysed the experimental samples after solvent extraction and derivatisation. This approach shows that the total lipid extract of the tars obtained was quite close to that of archaeological samples, especially for one of the samples manufactured.

\subsection{Samples}

Several manufacturing processes for making birch bark tar were known in antiquity. One of them, named the "double-pot" method, particularly well described in the medieval literature, was probably widespread in the past [29]. Therefore, we decided to use this method for producing our own birch bark tar. A known amount of white birch bark chips (approximatively $3 \mathrm{~kg}$ ) was put into a perforated ceramic vessel of $30 \mathrm{~cm}$ for its larger diameter (12 L vessel). The top of this pottery was covered with a lid and placed on the top of a second vessel. The watertightness between those two vessels was ensured by a strong lute made with potters' clay and organic temper. To follow the temperature evolution during the tar process, a thermocouple was placed inside the upper vessel. This double-pot system was then placed on a fire place, the vessel of the lower part buried in a pit and the top covered with wood that was set on fire (see scheme in reference [29]). During the operation, bark was slowly converted into tar and run through the hole in the lower pottery as a black, liquid and odoriferous substance. An amount of $24.5 \mathrm{mg}$ was collected after $6 \mathrm{~h}$ and the maximum temperature measured in the vessel was $450^{\circ} \mathrm{C}$.

The other reference sample of birch bark tar was made in the laboratory a few years ago, in a glass vial [6]. Briefly, $730 \mathrm{mg}$ of white birch bark were cut in small pieces and heated in a test tube for several minutes. The temperature reached, around $600{ }^{\circ} \mathrm{C}$, was measured with a thermocouple. A black and compact residue, that was kept in a closed glass tube until now, was obtained by this method.

\subsection{Commercial standards}

To identify with certainty some of the volatile organic compounds trapped on the polymeric fibres, a series of commercial standards was studied. With this aim, 2,6-dimethoxytoluene, 2,4-dimethylanisole and 2,3,6-trimethylphenol were purchased from Sigma-Aldrich (Milwaukee, WI, USA). 4Methoxyphenol, 2-methoxyphenol, 2-methoxy-4-methylphenol and 4-ethyl-2-methoxyphenol were purchased from Alfa Aesar (Ward Hill, MA, USA).

Two triterpenoids (betulin and lupeol), biomarkers of the total lipid extract of birch bark tar, were also analysed by GC and GC-MS. Betulin was purchased from Sigma-Aldrich and lupeol from Extrasynthese (Genay, France).

\subsection{Solvent extraction procedure}

A few milligrams of each material manufactured were sampled with a sterile scalpel blade or with a pipette, depending on the solid or liquid nature of the samples. Dichloromethane was added to obtain a $1 \mathrm{mg} \mathrm{mL}^{-1}$ solution. The solutions were then ultrasonicated $2 \times 20 \mathrm{~min}$ in dichloromethane (HPLC grade). An aliquot of the supernatant $(100 \mu \mathrm{L})$ was transferred to a $2 \mathrm{~mL}$ glass vial, evaporated until dryness under a gentle stream of nitrogen. Derivatisation was made using BSTFA [bis(trimethysilyl)trifluoroacetamide, Sigma-Aldrich]. Ten microlitres of dichloromethane, $5 \mu \mathrm{L}$ of pyridine and $50 \mu \mathrm{L}$ of BSTFA were added to the dry extract and the reaction took place for $20 \mathrm{~min}$ at room temperature. It was then evaporated to dryness under nitrogen $\left(40^{\circ} \mathrm{C}\right)$ and recovered with $20 \mu \mathrm{L}$ of dichloromethane. One microlitre of the sample was then injected into the chromatograph.

\subsection{SPME procedure}

Two SPME fibres of different polarities were chosen and purchased from Supelco: 50/30 $\mu \mathrm{m}$ divinylbenzene/Carboxen/polydimethylsiloxane (DVB/CAR/PDMS) and $100 \mu \mathrm{m}$ polydimethylsiloxane (PDMS). Samples were placed in a $20 \mathrm{~mL}$ vial fitted with a PTFE/silicon septum.

For liquid birch bark tar, sampling of $15 \mathrm{mg}$ was chosen against $5 \mathrm{mg}$ for the solid one because of the lower amount of matter available. The SPME fibre was introduced in the vial 
through the cap and maintained $1.5 \mathrm{~cm}$ above samples. Except in the case of analyses at room temperature $\left(23^{\circ} \mathrm{C}\right)$, the vial was placed into a heating block for performing the extraction at the chosen temperature. The fibre containing the concentrated analytes was then retracted, removed from the sample vial and the trapped components were desorbed $10 \mathrm{~min}$ in the injector port of the gas chromatograph set at $230^{\circ} \mathrm{C}$.

To determine the effects of heating temperature and time of SPME procedure, the sample vials were maintained at 23, 40,60 or $80^{\circ} \mathrm{C}$ for 15,30 or $60 \mathrm{~min}$. Adequate conditions of time and temperature were then chosen. The extraction was then realised three times with these conditions (time and temperature) to check the reproducibility of the headspace SPME procedure and of the GC analysis.

\section{5. $G C$ and $G C-M S$ analysis}

GC analyses were performed on a HP6890 gas chromatograph (Hewlett-Packard, Palo Alto, CA, USA) equipped with a split/splitless injector used in the splitless mode. Total lipid extracts of birch bark tars were separated on a CP-Sil 5 CB (Varian, Palo Alto, CA, USA) capillary column of $30 \mathrm{~m} \times 0.25 \mathrm{~mm}$ I.D., $0.25 \mu \mathrm{m}$ film thickness. The temperatures of injector and detector (flame ionization detection, FID) were 300 and $320^{\circ} \mathrm{C}$, respectively. The oven was programmed as follows: $50{ }^{\circ} \mathrm{C}$ for $2 \mathrm{~min}, 50-150{ }^{\circ} \mathrm{C}$ at $10^{\circ} \mathrm{C} \mathrm{min}^{-1}$ and $150-320^{\circ} \mathrm{C}$ at $4^{\circ} \mathrm{C} \mathrm{min}^{-1}, 320^{\circ} \mathrm{C}$ for $30 \mathrm{~min}$. The carrier gas was helium set at $1.5 \mathrm{~mL} \mathrm{~min}^{-1}$.

GC-MS analyses were performed on a HP5890 series II gas chromatograph, equipped with a split/splitless injector and coupled to a GCQ ion trap mass spectrometer (Finnigan, San Jose, CA, USA). Total lipid extracts were analysed using the same chromatographic conditions as those used in GC.

Volatile organic compounds were separated on a CP-Sil 8 CB low bleed (Varian) capillary column of $60 \mathrm{~m} \times 0.25 \mathrm{~mm}$ I.D. with a film thickness of $0.25 \mu \mathrm{m}$. The injector temperature was set at $230^{\circ} \mathrm{C}$ and the oven temperature programmed as follows: $35^{\circ} \mathrm{C}$ during $10 \mathrm{~min}, 35-270^{\circ} \mathrm{C}$ at $5^{\circ} \mathrm{C} \mathrm{min}^{-1}, 270^{\circ} \mathrm{C}$ during $30 \mathrm{~min}$. The carrier gas was helium at $1 \mathrm{~mL} \mathrm{~min}^{-1}$. Splitless mode was used. The temperature of the transfer line and the source of the mass spectrometer were 290 and $180^{\circ} \mathrm{C}$, respectively.

The mass spectrometer was operating in electron-impact mode $(\mathrm{EI})$ at $70 \mathrm{eV}$, in the scan range $m / z$ 33-650.

\section{Results and discussion}

\subsection{Chromatographic pattern of the total lipid extracts}

Chromatographic patterns of the tars experimentally produced are presented in Fig. 1. In both cases, triterpenoid constituents were detected and identified. The chromatograph of the solid tar is quite simple and presents two main peaks and two minor peaks. The main compounds were identified by comparison of their retention time with that of trimethylsilylated commercial standards, namely lupeol and betulin, triterpenoid components with a lupane skeleton that are biomarkers of white

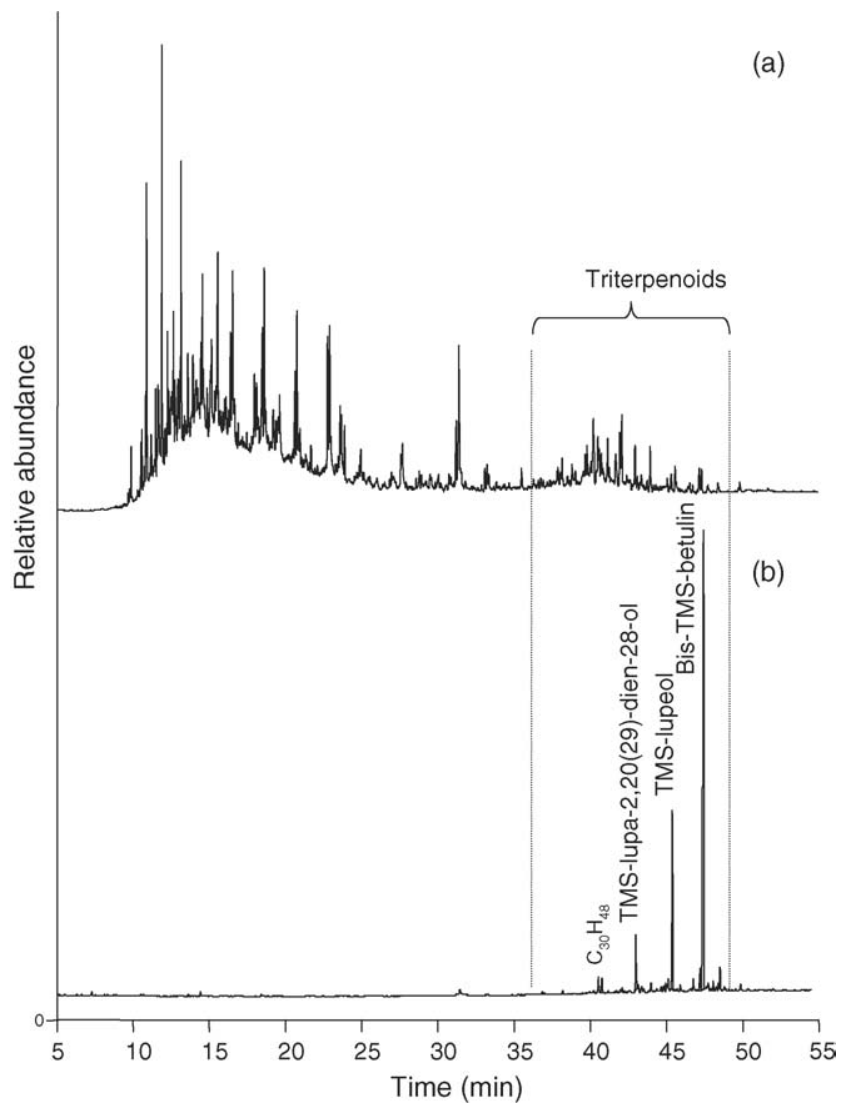

Fig. 1. GC-FID chromatograms of birch bark tars experimentally produced. (a) Liquid birch bark tar produced by the double-pot system; (b) solid sample produced in the laboratory by heating white birch bark in a test tube at $600{ }^{\circ} \mathrm{C}$.

birch bark [30-32]. GC-MS analyses confirmed these attributions. The component eluted just after $40 \mathrm{~min}$ was identified as a triterpenoid lupane $\mathrm{C}_{30} \mathrm{H}_{48}$, that is known to be formed during the tar process by dehydration of lupeol [8]. TMS lupa2,20(29)-dien-28-ol, a degradation marker formed by dehydration of betulin, was also identified by its mass spectrum $[6-8,12]$.

The set of molecular compounds identified, allied with the ratio between the different molecular constituents for solid tar, are in good agreement with the molecular composition of the total lipid extracts of birch bark tar described by several authors in the literature for archaeological samples issued from various environments $[3,6,7,12]$.

The liquid tar appears to be more complex. Besides a mixture of triterpenoids that were not all specifically identified, it contains a great number of more volatile constituents eluted before $30 \mathrm{~min}$. The complexity of the total lipid extract of the liquid tar is probably due to the manufacturing process. Indeed, $6 \mathrm{~h}$ in a closed ceramic was necessary to obtain this product and such conditions seem to greatly alter the structure of the initial triterpenoid biomarkers of birch bark. However, because the purpose of our study was not to reconstruct precisely the way of making tar during ancient times, we did not study in detail this chromatogram. Instead, we focused on the analysis of the volatile organic compounds emitted by the two products obtained, that were both odoriferous. 


\subsection{Choice of the SPME conditions}

\subsubsection{Choice of the fibre coatings}

The nature of the SPME fibre coating strongly conditions the effectiveness of HS-SPME sampling. However, in the case of birch bark tar, nothing was known on the nature of the volatile organic components emitted. Because the material of interest in this study belongs to the vegetable kingdom, mono- and/or sesquiterpenes were expected but many other volatile or semivolatile, more or less polar products, could also be emitted; it was thus necessary to choose a fibre that traps molecules with a large range of molecular weights presenting different polarities. The 50/30 $\mu \mathrm{m}$ DVB/CAR/PDMS corresponds to a fibre that was found to be one of the most effective for a wide range of compounds [28,33]. First analyses were thus performed with such a fibre which was indeed shown to be adapted to our purpose. Moreover, because of the possible presence of non-polar compounds that could be of interest, a $100 \mu \mathrm{m}$ PDMS fibre was also tested.

\subsubsection{Influence of the extraction time}

Before assessing the impact of exposure temperature, it was important to choose the most adapted time of extraction for obtaining a sufficient yield of extraction in a minimum of time. Liquid tar was thus extracted at $23^{\circ} \mathrm{C}$ (room temperature) after an exposure time of 15,30 and $60 \mathrm{~min}$. For each interval of time, GC-MS analysis was carried out to qualitatively and quantitatively compare the results obtained.

Whatever the extraction time, the chromatographic profiles were similar for each fibre: the same components were eluted and the relative intensities of the peaks were comparable. The same compounds were also eluted by both fibres but with different intensities. Fig. 2 shows two characteristic chromatograms obtained for liquid tar after $30 \mathrm{~min}$ of exposure at room temperature $\left(23^{\circ} \mathrm{C}\right)$ with both fibres tested. Because of the high number of components detected and separated, specific individual compounds were selected to compare the results obtained with various extraction conditions. The constituents chosen had to be present in notable amount in most of the chromatograms, whatever the exposure conditions. It was also necessary to avoid any constituent co-eluted with another one. Seven constituents (numbered 4, 5, 14, 20, 31, 48 and 56 in Table 1, chromatograms and graphs) corresponding to different chemical types with various polarities and molecular weights (an alkane, a sesquiterpenoid, a naphthalene derivative and four phenolic compounds) present these characteristics. Fig. 3 plots the chromatographic peak area counts for each of these compounds against the time of exposure when using the DVB/CAR/PDMS coating.

The amount of each constituent increases with time, but there is no significant preferential absorption or adsorption of one of the compounds versus another. This observation is also valid in the case of the experiment with the PDMS fibre (Fig. 4). It thus appears that exposing the fibres with an increasing time does not allow to elute a larger number of individual compounds, at least in the case of liquid birch bark tar freshly prepared. After the longest time of exposure tested $(60 \mathrm{~min})$, the equilibrium was not reached. However, because the chromatographic profiles

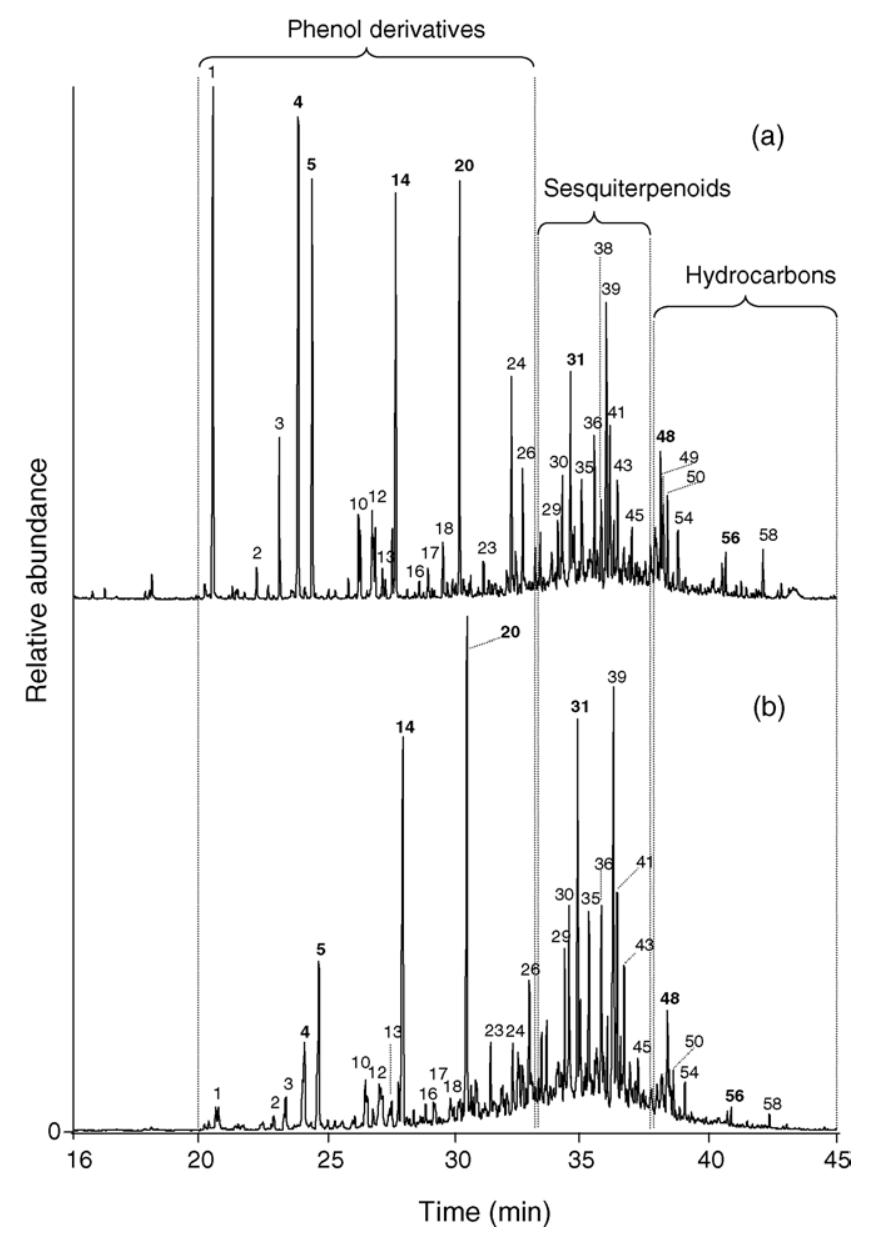

Fig. 2. Reconstructed ion chromatograms obtained by HS-SPME-GC-MS on the liquid tar at room temperature $\left(23^{\circ} \mathrm{C}\right)$ with an exposure time of $30 \mathrm{~min}$ (a) with the DVB/CAR/PDMS fibre and (b) with PDMS coating.

remain unchanged whatever the time of extraction, reaching the equilibrium was not essential since a large range of molecular constituents were rapidly eluted and that their proportion was not modified through time [34-36].

Concerning the solid tar, a single test was performed at room temperature, using an exposure time of $30 \mathrm{~min}$, due to the low amount of matter available. Almost no volatile compound was

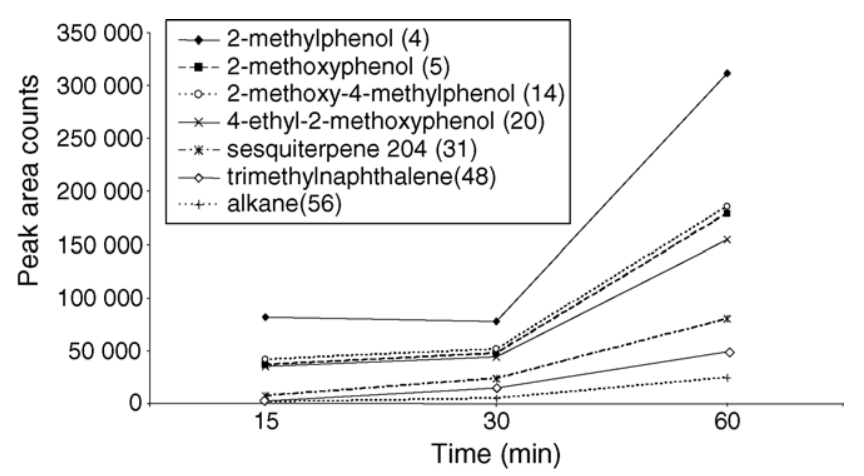

Fig. 3. SPME absorption time profiles with an exposure at room temperature using the DVB/CAR/PDMS fibre. The data obtained correspond to exposure time of 15, 30 and $60 \mathrm{~min}$. Numbers between brackets: numbering of individual compounds in Table 1. 
Table 1

List of molecular constituents identified in the VOCs of experimental birch bark tars

\begin{tabular}{|c|c|c|c|c|c|c|c|}
\hline \multirow[t]{2}{*}{$\mathrm{PN}$} & \multirow[t]{2}{*}{ Chemical family } & \multirow[t]{2}{*}{ Identification } & \multirow[t]{2}{*}{ MW } & \multicolumn{2}{|l|}{ Liquid tar } & \multicolumn{2}{|l|}{ Solid tar } \\
\hline & & & & $\begin{array}{l}\% \mathrm{DVB} / \mathrm{CAR} / \mathrm{PDMS} \\
60^{\circ} \mathrm{C} 30 \mathrm{~min}\end{array}$ & $\begin{array}{l}\% \text { PDMS } \\
40^{\circ} \mathrm{C} 30 \mathrm{~min}\end{array}$ & $\begin{array}{l}\% \mathrm{DVB} / \mathrm{CAR} / \mathrm{PDMS} \\
80^{\circ} \mathrm{C} 30 \mathrm{~min}\end{array}$ & $\begin{array}{l}\% \text { PDMS } \\
80^{\circ} \mathrm{C} 30 \mathrm{~min}\end{array}$ \\
\hline 1 & Phenol derivative & Phenol & 94 & 62 & 32 & 3 & n.d. \\
\hline 2 & Alkene or ester & & 112 & 6 & 17 & n.d. & n.d. \\
\hline 3 & Phenol derivative & & 108 & 25 & 23 & 3 & n.d. \\
\hline 4 & Phenol derivative & 2-Methylphenol & 108 & 100 & 57 & 22 & n.d. \\
\hline 5 & Phenol derivative & 2-Methoxyphenol & 124 & 61 & 50 & 29 & 4 \\
\hline 6 & Phenol derivative & Dimethylphenol & 122 & 2 & 7 & n.d. & n.d. \\
\hline 7 & Amine & & 169 & Trace & n.d. & 25 & n.d. \\
\hline 8 & Phenol derivative & Dimethylphenol & 122 & 4 & 16 & n.d. & n.d. \\
\hline 9 & Phenol derivative & & 122 & 14 & 33 & n.d. & n.d. \\
\hline 10 & Phenol derivative & & 122 & 11 & 30 & 4 & n.d. \\
\hline 11 & & $\begin{array}{l}\text { Benzene-(1-methyl-4-(1- } \\
\text { methylethyl)? }\end{array}$ & 134 & 1 & 7 & 17 & 5 \\
\hline 12 & Phenol derivative & & 122 & 27 & 43 & n.d. & n.d. \\
\hline 13 & Phenol derivative & & 122 & 14 & n.d. & 15 & n.d. \\
\hline 14 & Phenol derivative & $\begin{array}{l}\text { 2-Methoxy-4- } \\
\text { methylphenol }\end{array}$ & 138 & 49 & 25 & 80 & 19 \\
\hline 15 & Phenol derivative & Trimethylphenol & 136 & 2 & 8 & Trace & n.d. \\
\hline 16 & Phenol derivative & Trimethylphenol & 136 & 4 & Trace & Trace & n.d. \\
\hline 17 & Phenol derivative & 2,3,6-Trimethylphenol & 136 & 8 & 11 & n.d. & n.d. \\
\hline 18 & Phenol derivative & $\begin{array}{l}\text { Propylphenol + 1,2- } \\
\text { benzenediol-3-methyl }\end{array}$ & $136+124$ & 24 & n.d. & Trace & n.d. \\
\hline 19 & Alcohol & $\begin{array}{l}\text { 1,2-Benzenediol-3- } \\
\text { methoxy }\end{array}$ & 140 & 8 & n.d. & 2 & n.d. \\
\hline 20 & Phenol derivative & 4-Ethyl-2-methoxyphenol & 152 & 64 & 95 & 100 & 37 \\
\hline 21 & Alcohol & 3-Methyl,1-2,benzenediol & 124 & 21 & n.d. & n.d. & n.d. \\
\hline 22 & & $\begin{array}{l}\text { Benzene-(3-methyl-2- } \\
\text { butenyl)? }\end{array}$ & 146 & Trace & 11 & 6 & 2 \\
\hline 23 & Naphthalene derivative & Methylnaphthalene & $141-142$ & 5 & 12 & 34 & n.d. \\
\hline 24 & Phenol derivative & Dimethoxyphenol & 154 & 47 & 23 & 52 & 10 \\
\hline 25 & Phenol derivative & $\begin{array}{l}\text { Phenol,2-methoxy-4-(1- } \\
\text { propenyl) }\end{array}$ & 164 & 11 & 10 & 14 & 12 \\
\hline 26 & Phenol derivative & $\begin{array}{l}\text { Phenol,2-methoxy-4- } \\
\text { propyl }\end{array}$ & 166 & 22 & 45 & 25 & 12 \\
\hline 27 & Sesquiterpenoid & Sesquiterpene & 204 & n.d. & Trace & n.d. & n.d. \\
\hline 28 & Monoterpenoid & Vanillin & 152 & n.d. & n.d. & 38 & 10 \\
\hline 29 & Sesquiterpenoid & Sesquiterpene & 202 & 7 & 44 & 45 & 19 \\
\hline 30 & Sesquiterpenoid & Sesquiterpene & 204 & 14 & 63 & 12 & 80 \\
\hline 31 & Sesquiterpenoid & Sesquiterpene & 204 & 18 & 76 & 56 & 39 \\
\hline 32 & Sesquiterpenoid & Sesquiterpene & 202 & 9 & n.d. & 23 & n.d. \\
\hline 33 & & & 168 & 24 & n.d. & 23 & 18 \\
\hline 34 & Sesquiterpenoid & Sesquiterpene & 204 & n.d. & 59 & 37 & n.d. \\
\hline 35 & & & $164+204$ & 19 & n.d. & 23 & 20 \\
\hline 36 & Naphthalene derivative & Ethylnaphthalene & 156 & 24 & 67 & 15 & n.d. \\
\hline 37 & Alkene? & & $?$ & 30 & 22 & n.d. & n.d. \\
\hline 38 & Sesquiterpenoid & Sesquiterpene & 202 & Trace & 28 & 38 & 59 \\
\hline 39 & Sesquiterpenoid & Sesquiterpene & 204 & 18 & 100 & n.d. & 55 \\
\hline 40 & Phenol derivative & $\begin{array}{l}\text { Phenol,2-methoxy-4- } \\
\text { propyl }\end{array}$ & 166 & Trace & n.d. & 48 & n.d. \\
\hline 41 & & & 188 & 18 & 47 & 25 & 25 \\
\hline 42 & & & $159-188$ & 8 & 17 & 15 & 15 \\
\hline 43 & Sesquiterpenoid & Sesquiterpene & 202 & 10 & 44 & 72 & 100 \\
\hline 44 & & & 182 & 25 & n.d. & 34 & 20 \\
\hline 45 & Sesquiterpenoid & Calamenene & 202 & 7 & n.d. & 15 & n.d. \\
\hline 46 & & & 186 & 9 & 12 & 27 & 18 \\
\hline 47 & Naphthalene derivative & & 200 & 16 & 11 & 29 & n.d. \\
\hline 48 & Naphthalene derivative & Trimethylnaphthalene & 170 & 18 & 43 & 20 & 10 \\
\hline 49 & & & 186 & 13 & n.d. & 24 & 33 \\
\hline 50 & Alkane & & & 11 & n.d. & n.d. & n.d. \\
\hline 51 & & Phtalate & $149-177$ & n.d. & n.d. & 11 & 23 \\
\hline 52 & & & 196 & 7 & n.d. & 7 & trace \\
\hline 53 & & & 200 & 11 & 12 & 34 & n.d. \\
\hline
\end{tabular}


Table 1 (Continued)

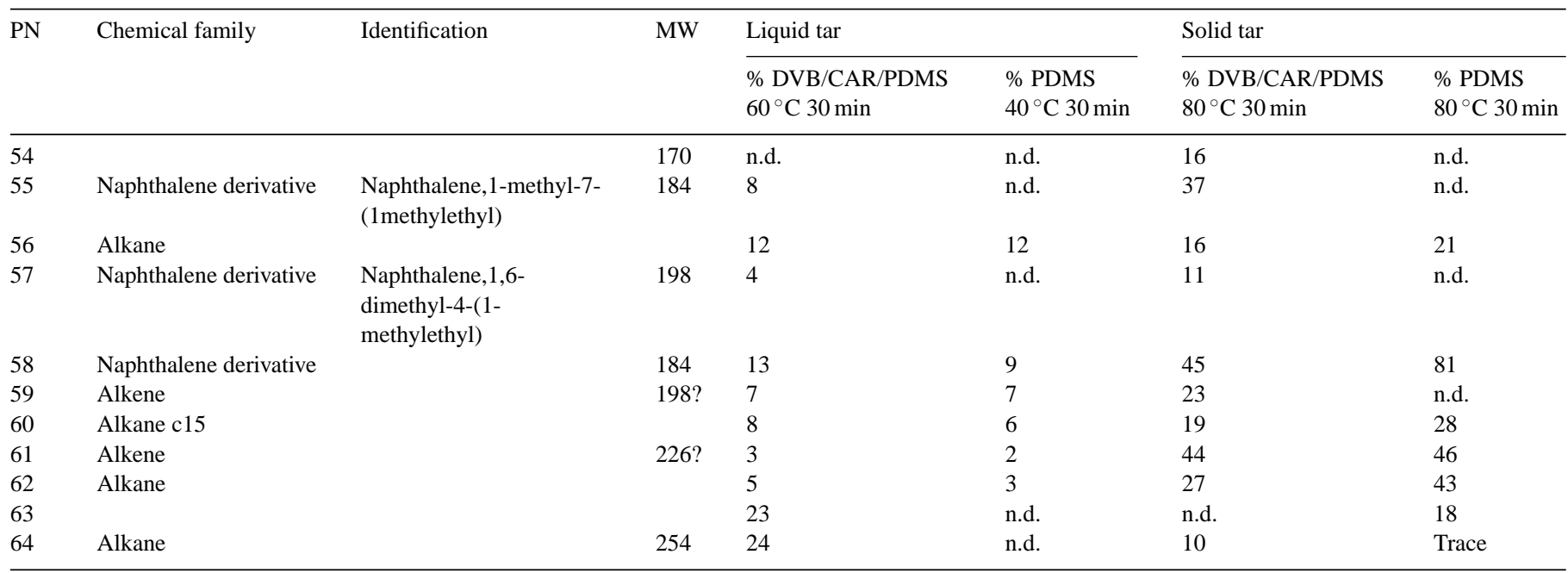

detected. For this sample, that was produced a few years ago, in an open tube, the most volatile compounds may have been lost and a heating operation during fibre exposure was necessary to favour the desorption of the volatile compounds trapped into the solid tar.

These results led us to choose $30 \mathrm{~min}$ as exposure time. Indeed, this time was considered as a good compromise to obtain a sufficient yield of extraction with a time that allows a reasonable number of extractions and analyses per day.

\subsubsection{Influence of the temperature of extraction}

With a $30 \mathrm{~min}$ extraction time, four extraction temperatures were tested: $23^{\circ} \mathrm{C}$ (room temperature), 40, 60 and $80^{\circ} \mathrm{C}$.

According to the graph presented on Fig. 5 corresponding to the experiment with the DVB/CAR/PDMS, the compounds may be classified into two main categories depending on their yield of extraction. The first class contains three components (an alkane, a sesquiterpene and trimethylnaphthalene) which present quite a low efficiency of extraction compared to the others. For these compounds, increasing the temperature of extraction does not lead to a significant improvement of the abundance of the VOCs trapped on the fibre. The abundance of the alkane increases more

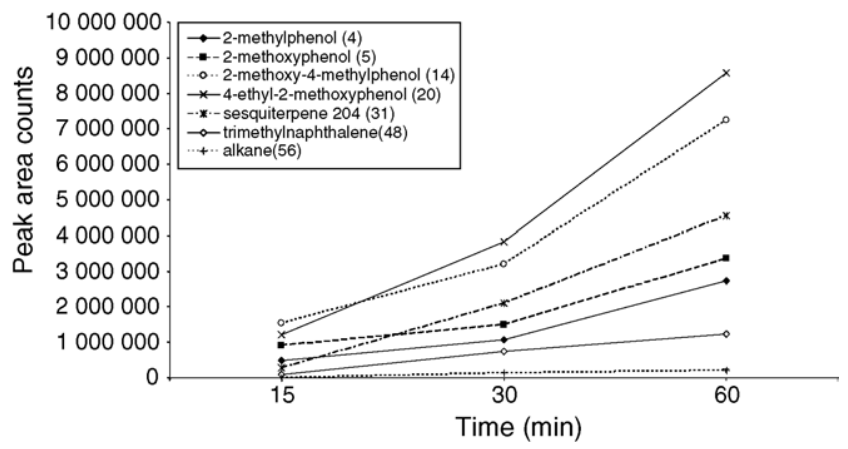

Fig. 4. SPME absorption time profiles with an exposure at room temperature using the PDMS fibre. The data obtained correspond to exposure time of 15, 30 and $60 \mathrm{~min}$. Numbers between brackets: numbering of individual compounds in Table 1. slowly after a $60^{\circ} \mathrm{C}$ temperature of exposure than at lower temperature, probably indicating that equilibrium is almost reached at $80{ }^{\circ} \mathrm{C}$.

The second class comprises four phenols with various polarities and molecular weights from 108 to 152 (compounds 4, 5, 14 and 20). For each of these compounds, an increase in the temperature results in an important increase in the concentration of VOCs trapped on the fibre coating for temperature lower than $60^{\circ} \mathrm{C}$. Beyond this temperature, the yield of extraction of two phenolic components still strongly increases (compounds 5 and 14). The abundance of 2-methylphenol (compound 5) and 4ethyl-2-methoxyphenol (compound 20) increases at a lower rate than below $60^{\circ} \mathrm{C}$, which indicates that equilibrium is not far to be reached for these compounds. The evolution of the yield of extraction of the four phenol derivatives studied in detail clearly indicates that the more polar and the lighter the phenol, the more important the improvement of the yield of extraction versus temperature.

To fit our objectives, it thus appears that an exposure temperature of $60^{\circ} \mathrm{C}$ with an extraction time of $30 \mathrm{~min}$ is an interesting compromise for analysing birch bark tar.

Considering the PDMS fibre coating, the chromatographic pattern was greatly modified depending on exposure tempera-

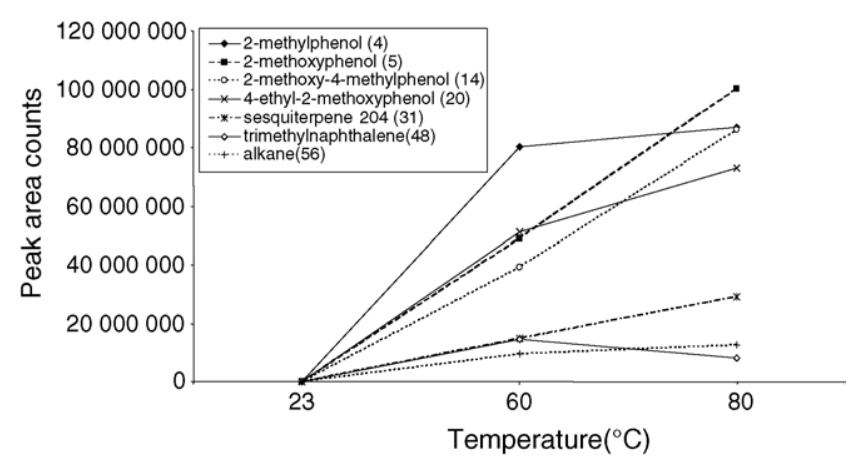

Fig. 5. Temperature profiles of seven individual compounds obtained with DVB/CAR/PDMS fibre. The data were obtained for an exposure time of $30 \mathrm{~min}$ Numbers between brackets: numbering of individual compounds in Table 1. 


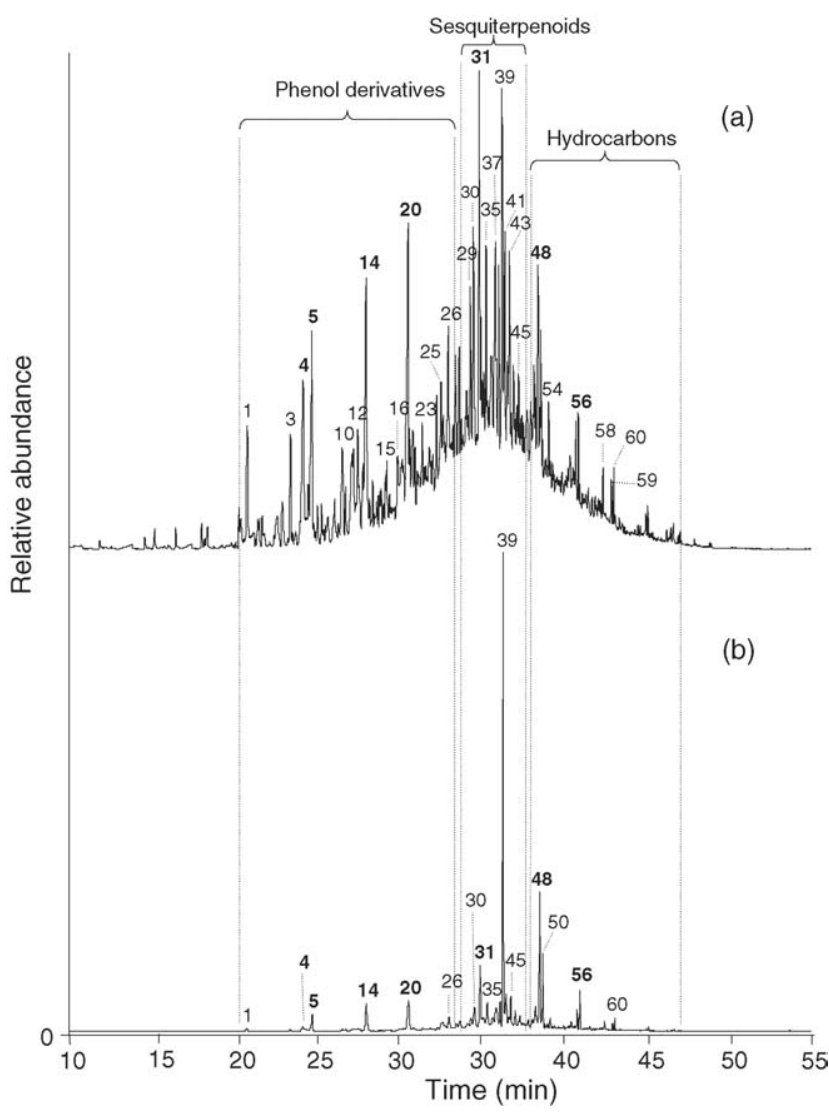

Fig. 6. Comparison of reconstructued ion chromatograms obtained with the PDMS fibre for the analysis of liquid birch bark tar at different temperatures of extraction for an exposure time of $30 \mathrm{~min}$ : (a) $40^{\circ} \mathrm{C}$; (b) $60^{\circ} \mathrm{C}$.

ture (Fig. 6) because the extraction yield of the alkane, as well as that of the low polarity compounds, strongly increases with temperature (Fig. 7). This is very detrimental for the characterisation of an unknown archaeological substance, which must be preferentially based on a large number of molecular constituents.

Temperatures higher than $40^{\circ} \mathrm{C}$ should thus be avoided for characterising birch bark tar with a PDMS fibre.

This study confirms the efficiency of the DVB/CAR/PDMS fibre for the analysis of the VOCs emitted by natural substances and shows for the first time the interest of HS-SMPE GC-MS for the analysis of birch bark tar, a substance of great interest

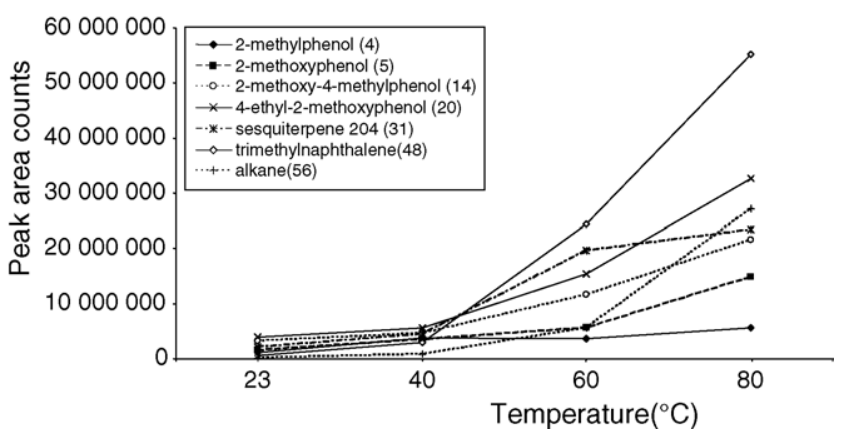

Fig. 7. Temperature profiles of seven individual compounds obtained with PDMS fibre. The data were obtained for an exposure time of $30 \mathrm{~min}$. Numbers between brackets: numbering of individual compounds in Table 1 .

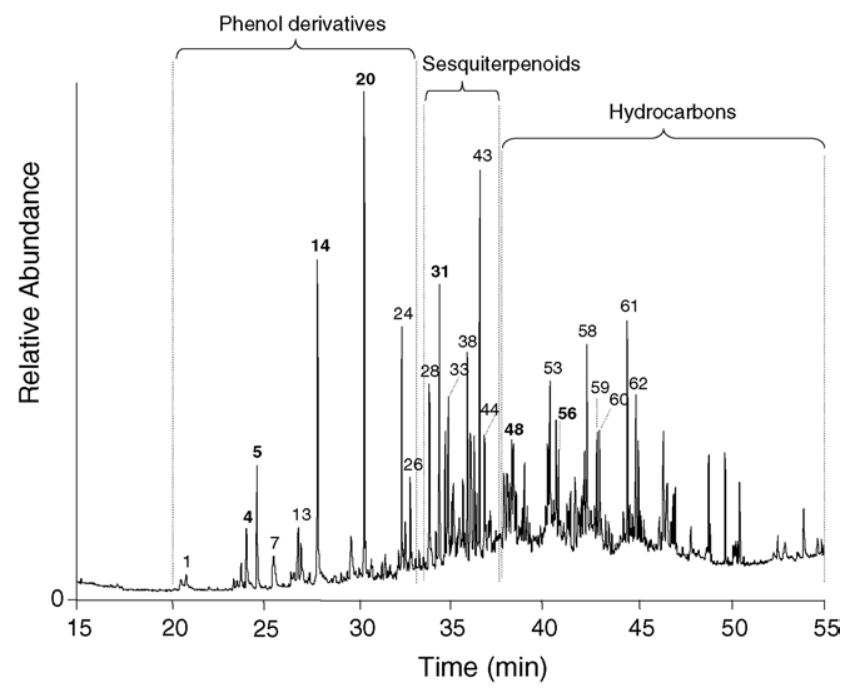

Fig. 8. Reconstructed ion chromatogram obtained by HS-SPME-GC-MS of a sample of solid birch bark tar with an extraction time of $30 \mathrm{~min}$ and an exposure temperature of $80^{\circ} \mathrm{C}$ with a DVB/CAR/PDMS fibre.

in the field of archaeology. According to the various conditions of sample treatment tested in this study, a time of extraction of 30 min together with a temperature of exposure of $60^{\circ} \mathrm{C}$ appears to be a good compromise for eluting a large number of molecular compounds with a sufficient yield of extraction. In the case of the PDMS fibre, it would be preferable to work with a temperature of $40{ }^{\circ} \mathrm{C}$ and an exposure time of $30 \mathrm{~min}$.

The conditions tested on the liquid sample could not all be performed on the solid tar due to the low amount of matter available. In particular, because of the higher efficiency of the DVB/CAR/PDMS fibre versus the apolar one, it was decided to only assess the influence of extraction temperature using this fibre. The experiments were carried out with an exposure time of $30 \mathrm{~min}$ and extraction temperatures of 23 (room temperature), 40,60 and $80^{\circ} \mathrm{C}$; the best results were obtained with this last temperature (Fig. 8).

\subsection{Molecular characterisation of the volatile organic components}

The chromatograms obtained are very complex and provide a great number of individual compounds (Figs. 2, 6 and 8). Because of the similarities of the chromatographic patterns, the results of the identification of the VOCs are presented for the optimised conditions for liquid and solid birch bark tars (Table 1).

The chromatograms may be divided into three main zones depending on the nature of the molecular constituents eluted. At retention times below $33 \mathrm{~min}$, the chromatogram is dominated by phenolic compounds. Between 33 and 38 min, sesquiterpenoids are eluted. The end of the chromatograms shows the presence of hydrocarbons.

Sixty-four individual compounds were separated and detected, from which 53 were undoubtedly identified or at least attributed to a class of chemical compounds. These molecular constituents were classified into four categories of chemical 

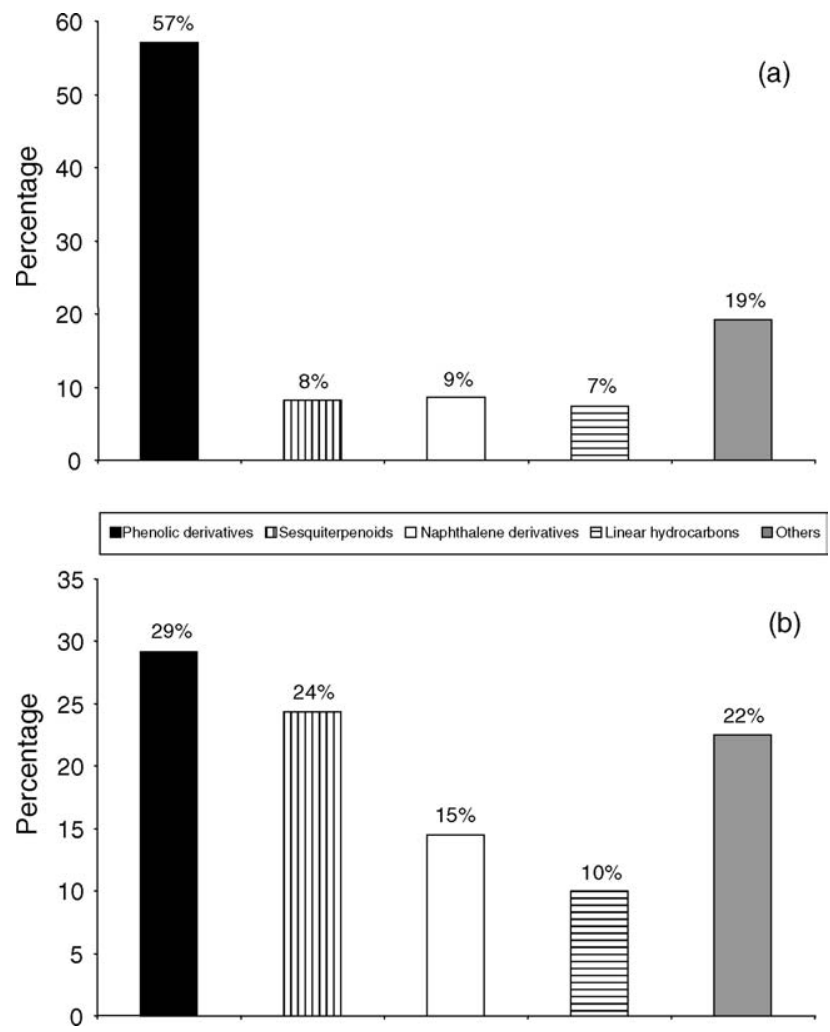

Fig. 9. Distributions of the different molecular types identified after sample treatment involving the DVB/CAR/PDMS fibre for (a) the liquid birch bark with an extraction time and temperature of, respectively, $30 \mathrm{~min}$ and $60^{\circ} \mathrm{C}$ and for (b) the solid sample with an exposure time and temperature of $30 \mathrm{~min}$ and $80^{\circ} \mathrm{C}$, respectively.

families, namely phenolic compounds, sesquiterpenoids, naphthalene derivatives and linear hydrocarbons (Fig. 9). The liquid birch bark tar vapours were shown to be predominantly constituted of phenolic derivatives $(57 \%)$, with a proportion varying between 7 and $9 \%$ of the other molecular constituents. The same classes of molecules were emitted by the solid sample of birch bark tar but with a different distribution. Although phenolic components are still predominant, sesquiterpenes are present in roughly the same amount (29\% for the first ones and $24 \%$ for the latter). The other families of constituents represent less than $15 \%$ of the detected compounds.

The difference of distribution in the main chemical categories of molecular compounds between the two kinds of samples may be explained by their ways of manufacture. Indeed, liquid birch bark tar was produced in a sealed pot and directly transferred into a vial; the loss of volatile constituents was thus minimised. In the case of solid tar, the process was performed in an open glass tube and some volatiles were probably lost during the procedure. All these parameters may explain that the vapours of the solid sample were less concentrated in the most volatile compounds, namely phenolic compounds versus sesquiterpenoids.

Most of the phenolic derivatives are known to be of plant origin [37]. They are products of secondary metabolites of plants [38] and occur either as free low molecular constituents or as part of polymerised materials. They are particularly important in three groups of biopolymers-the lignin of the plant cell walls, the black melanin pigments of plants and tannin of woody plants [37]. The phenolic compounds identified in birch bark tar may thus be related to the tannin and lignin content of the bark. Whether these phenolic derivatives may be used for their chemotaxonomic value or not is still difficult to assess since the SPME experiments were only performed on one species. Further works should provide new data on this point. Nevertheless, the presence of these molecular compounds should be of great interest for making the difference between wood or bark-derived materials versus plant resins. This is an important and heuristic perspective for identifying archaeological adhesives made of tars or resins in a non-destructive way.

A set of 10 sesquiterpenoids were detected owing to fragmentograms reconstructed from the total ionic current at $m / z 202$ and 204 , respectively, corresponding to $\mathrm{C}_{15} \mathrm{H}_{22}$ and $\mathrm{C}_{15} \mathrm{H}_{24}$ raw formula. Because of the complexity of the chromatogram obtained in the region of sesquiterpenoid retention times, of the co-elution of several individual compounds and of the presence of several isomers, all these compounds were not individually identified. However, the mass spectrum of some of them clearly indicates a structure of phenylalkane type because of characteristic fragments at $\mathrm{m} / \mathrm{z}, 77,91,105$ and 119 [39]. Furthermore, for one sesquiterpenoid (compound 45), the mass spectrum obtained is consistent with that of calamenene (Fig. 10).

These biomarkers are widespread in the plant kingdom; they are secondary metabolites of plants and are usually present as minor components, but they endow characteristic flavours to the products in which they are present [37]. To our knowledge, this is the first time that such constituents are extracted from birch bark tars, eventhough calamenene has already been mentioned in essential oil from birch buds [40]. They may partly explain the odoriferous nature of birch bark tar and they could further be used for the identification of this material in archaeological context.

If phenolic and sesquiterpenoid components were the two main groups of natural constituents detected in the volatiles emitted by the samples investigated in this study, other compounds which belong to linear hydrocarbons or naphthalene derivatives were also detected, but it is still difficult to assess their precise origin.

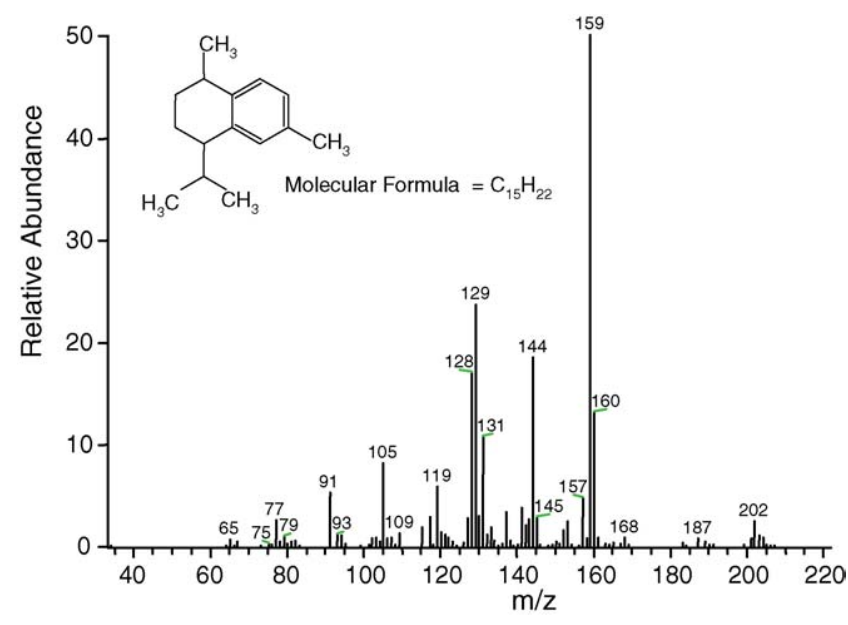

Fig. 10. Mass spectrum attributed to calamenene structure. 


\section{Conclusions}

The main goal of this research was to assess the feasibility of studying birch bark tar, a material of great importance in the archaeological field, by a non-destructive way using HSSPME treatment before GC-MS analysis. The analyses were performed on two liquid and solid tars manufactured by different processes. In both cases, volatile organic components were emitted by these substances and they could be easily trapped and characterised using adequate conditions of time and temperature extractions. DVB/CAR/PDMS fibre was found to be more efficient that PDMS fibre for extracting a large range of compounds. A time of $30 \mathrm{~min}$ was sufficient for reaching a satisfying yield of extraction whatever the sample considered. A higher temperature $\left(80^{\circ} \mathrm{C}\right.$ instead of $\left.60^{\circ} \mathrm{C}\right)$ was necessary for extracting the VOCs from the solid tar than those issued from the liquid tar.

Several types of molecular constituents, particularly phenolic derivatives and sesquiterpenoid isomers, that could be further used as biomarkers, were extracted, detected and identified for the first time in birch bark tar.

The results obtained are thus very promising for the future identification of birch bark tar from archaeological origin by this analytical methodology. Further studies will necessarily comprise the development of specific in situ sampling procedures, directly at the archaeological site, just after excavation. The volatile compounds emitted could therefore be trapped as early as the archaeological artefacts are discovered and recovered from their sediment matrix. In particular, when adhesives are still preserved in ceramic vessels, it will be possible to directly insert the fibre inside the pottery for trapping the VOCs, providing a totally non-destructive analytical method for investigating the nature of the glues exploited through time by our ancestors.

\section{Acknowledgements}

This study was supported by the financial contribution of the French "Ministère de la Culture et de la Communication" in a National Research Program entitled "Programme National de Recherche sur la Connaissance et la Conservation des Matériaux du Patrimoine Culturel" (PNRC 2003-2005). The authors also wish to thank the Research Group ChimArt (GdR 2114 CNRS-Ministère de la Culture) for support to this research. They also sincerely thank Dr. Guillaume Dupuis for his advise during the writing of this paper.

\section{References}

[1] J. Koller, U. Baumer, D. Mania, Eur. J. Archaeol. 4 (2001) 385.

[2] J.M. Grünberg, Antiquity 76 (2002) 15.

[3] E.M. Aveling, C. Heron, Ancient Biomol. 2 (1998) 69.

[4] E.M. Aveling, C. Heron, Antiquity 73 (1999) 579.

[5] K. Evans, C. Heron, Chem. Ind. 12 (1993) 446.
[6] M. Regert, J.M. Delacotte, M. Menu, P. Pétrequin, C. Rolando, Ancient Biomol. 2 (1998) 81.

[7] M. Regert, S. Vacher, C. Moulherat, O. Decavallas, Archaeometry 45 (2003) 101.

[8] M. Regert, J. Sep. Sci. 27 (2004) 244.

[9] E.W.H. Hayek, P. Krenmayr, H. Lohninger, U. Jordis, W. Moche, F. Sauter, Anal. Chem. 62 (1990) 2038.

[10] E.W.H. Hayek, P. Krenmayr, H. Lonhinger, U. Jordis, F. Sauter, W. Moche, Fresenius J. Anal. Chem. 340 (1991) 153.

[11] S.N. Dudd, R.P. Evershed, Tetrahedron Lett. 40 (1999) 359.

[12] S. Charters, R.P. Evershed, L.J. Goad, Archaeometry 35 (1993) 91.

[13] W. Sandermann, Tech. Beitr. Archäol. 2 (1965) 58.

[14] H. Funke, Chemische-analytische Untersuchungen verschiedener archäologischer Funde, unpublished dissertation Thesis, University of Hamburg, 1969.

[15] D. Binder, G. Bourgeois, F. Benoist, C. Vitry, Rev. Archéom. 14 (1990) 37.

[16] D. Neubauer, P. Schwörer, Zur Herstellung von Birkenteer im Neolithikum, Actes du colloque international "expérimentation en archéologie: bilan et perspectives", Hamburg, 1988.

[17] R.P. Belardi, J. Pawliszyn, Water Pollut. Res. J. Can. 24 (1989) 179.

[18] H. Kataoka, H.L. Lord, J. Pawliszyn, J. Chromatogr. A 880 (2000) 35.

[19] M. Riu-Aumatell, M. Castellari, E. Lopez-Tamames, S. Galassi, S. Buxaderas, Food Chem. 87 (2004) 627.

[20] M. Cocchi, C. Durante, G. Foca, D. Manzini, A. Marchetti, A. Ulrici, Chemom. Intell. Lab. Syst. 71 (2004) 129.

[21] D.C. Frank, C.M. Owen, J. Patterson, Lebensm.-Wissensch. Technol. 37 (2004) 139

[22] J.E. Hong, H. Pyo, S.J. Park, W. Lee, Anal. Chim. Acta 539 (2005) 55.

[23] N. Fucci, N. De Giovanni, M. Chiarotti, For. Sci. Int. 134 (2003) 40.

[24] Y.F. Sha, S. Shen, G.L. Duan, J. Pharm. Biomed. Anal. 37 (2005) 143.

[25] V.A. Isidorov, V.T. Vinogorova, K. Rafalowski, Atmospheric Environ. 37 (2003) 4645

[26] A. Zander, A.G. Bishop, P.D. Prenzler, Anal. Chim. Acta 530 (2005) 325.

[27] S. Hamm, J. Bleton, A. Tchapla, J. Sep. Sci. 27 (2004) 235.

[28] A. Lattuati-Derieux, S. Bonnassies-Termes, B. Lavédrine, J. Chromatogr. A 1026 (2004) 9.

[29] C.W. Beck, E.C. Stout, D. Todtenhaupt, A. Kurzweil, Br. Archaeol. Rep. 1043 (2002) 179

[30] M.M. O'Connell, M.D. Bentley, C.S. Campbell, B.J.W. Cole, Phytochemistry 27 (7) (1988) 2175.

[31] E.W.H. Hayek, U. Jordis, W. Moche, F. Sauter, Phytochemistry 28 (1989) 2229.

[32] R. Ekman, Holzforschung 37 (1983) 205.

[33] C. Bicchi, S. Drigo, P. Rubiolo, J. Chromatogr. A 892 (2000) 469.

[34] B. Schäfer, P. Hennig, W. Engewald, J. High Resolut. Chromatogr. 18 (1995) 587.

[35] M. An, T. Haig, P. Hatfield, J. Chromatogr. A 917 (2001) 245.

[36] S. Hamm, E. Lesellier, J. Bleton, A. Tchapla, J. Chromatogr. A 1018 (2003) 73.

[37] J. Mann, R.S. Davidson, J.B. Hobbs, D.V. Banthorpe, J.B. Harborne, Natural Products: Their Chemistry and Biological Significance, first ed., Longman, London, 1994.

[38] L. Bravo, Nutr. Rev. 56 (1998) 317.

[39] F.W. McLafferty, Interpretation of Mass Spectra, fourth ed., University Science Boos, Mill Valley, CA, 1996.

[40] B. Demirci, D.H. Paper, F. Demirci, K. Hüsnü Can Baser, G. Franz, Evidence-based Complementary and Alternative Medicine, 2004. Available on the internet http://ecam.oxfordjournals.org/cgi/reprint/neh041v1. pdf. 